\title{
Communication and nurturing to sustain collaborative partnership
}

\author{
Suhaini Muda ${ }^{l, *}$ \\ ${ }^{1}$ School of Multimedia Technology and Communication, Universiti Utara Malaysia, 06010 UUM \\ Sintok, Kedah
}

\begin{abstract}
One of the major challenges of sustaining collaborative partnership in a longstanding community service organisation in the study involves ambiguous communication and cultural constrains among the stakeholders which due to the lack of communication and nurturing in the relationships. Based on the responses of multiple stakeholders, this paper brings forward the discussion on the need for communication and nurturing, the aspects which importance is commonly known but often being disregarded in the collaborative settings.
\end{abstract}

\section{INTRODUCTION}

This qualitative case study was done in Malaysia within the context of a particular community service organisation (CyberCare), a non-governmental organisation (NGO), aiming to improve the life of the children in orphanages through the mechanism of collaborative partnership between various stakeholders. Numerous programmes and activities have been carried out since 1998. The findings of this study bring together the views of multiple stakeholders concerning the challenges of sustaining collaborative partnership in a longstanding community service organisation. This paper will discuss one of the major challenges which involve the issue of ambiguous communication and cultural constrains from the perspective of the selected stakeholders which includes five CyberCare, four corporate, two other $\mathrm{NGO}$, nine volunteer, and nine orphanage administrator representatives. The paper flows from the review of the literature to the brief of findings, and discussion and conclusion.

\section{Communication and nurturing}

The sustainability of collaborative partnership has been connected by a number of authors to transparent communication and members continuously nurturing the relationship [1-5]. The importance of constant communication and nurturing in maintaining and sustaining collaborative partnership has been discussed extensively in the literature. This is especially obvious in that in which the scholars emphasise collaboration as an interactive

*Corresponding author: suhaini@uum.edu.my 
process [1,3] and as emerging processes [6-8]. These writers argue that collaboration evolves as participants interact throughout the course of collaboration. They also emphasise the importance of collaborators being involved in constant communication and nurturing. Huxham6 describes the nurturing in collaborative partnership in terms of a gardening metaphor. In this context, fragile plants need gentle care, and an overgrown garden needs more decisive tactics like chopping down excess growth, pulling up weeds, and caring for the plants that have been overpowered by others to nurture the plants and garden back to health [6].

The reasons why so many writers stress the need for constant communication is clarified by Wildavsky [8]. He argues that when collaborators come from different fields or bring widely varying perspectives and backgrounds, there is often a gap between expectations and understandings. He claims that the only way to bridge the gap is through communication over time among all the participants. In another study, the authors 11 suggest that established informal relationships and communication links are one of the factors in the success of community collaborations. In their study, the community collaboration used both formal and informal communication which gave the mixture of formal and informal ways of building and sustaining collaborative relationships. The study showed that the members of the collaboration were able to balance the informal nature of communication with their capability to communicate about formal and professional issues in an open and effective way. Consequently, the personal connections the members had to each other made them more willing to make efforts to resolve any arising issues together because they shared personal relationships.

The significant role of communication in sustaining a successful partnership is further discussed in reports by the multi-stakeholder partnership group, Global Knowledge Partnership (GKP) [9]. This work claims that it is important for the partners to maintain regular contact with each other, thereby preventing differences from becoming conflicts. Rather, through regular communication, issues can be jointly solved. GKP [9] suggests:

If the original set of agreements governing the partnership has been properly structured, ensuring on-going communication and transparency should be no more than a question of implementing the agreed procedures" ( $\mathrm{p} 25)$.

In this claim, the GKP also strongly relates constant communication with collaborative partnership agreement where it is believed that a well-structured agreement will help in the smooth running of the implementation process through communication and transparency. However, as has been discussed, it is a very difficult task because the process of reaching agreement itself is time-consuming, and partners come with different perspectives and expectations.

Huxham and Vangen [2,10] and Vangen and Huxham [5,11] emphasise the need for nurturing to address the various challenges. They specifically stress the importance of constant nurturing in coping with the challenges of a multiplicity of aims, power imbalances, sustaining trust, multifaceted membership structures, the dynamic of collaborative structures, and supporting leadership activities and encouraging community involvement in collaborative partnership [2,11]. In terms of managing the barriers of time and energy, Wildavsky [8] also suggests careful nurturing as a route to renewing enthusiasm as the partnership goes along.

It has been argued that continuous nurturing of the relationship is essential to address these challenges even in situations where collaboration is working well with a good degree of trust [5]. This continuous effort is needed to ensure that a sufficient level of trust can be maintained [5,11]. Despite the importance of nurturing, undertaking it is not easy in practice. Huxham and Vangen [2] claim that the main challenge in managing membership 
structures and dynamism is "learning how to identify, live with and progress despite ambiguity and complexity" [2] with constant nurturing [2,12] like through constant communication via email and social media networks. Many other authors also agree with the need to nurture the collaborative or partnership process and the challenges in practice. For example, Prins [13] who shares her experience as a process consultant or facilitator for multiparty collaboration in the context of foster care admits that there is a tension between the great need to take time to nurture the process and the need to produce results as expected by the collaborative managers of the collaborative project. The reviewed of the literature show that communication and nurturing are critical concerns in sustaining collaborative partnership

\section{AMBIGUOUS COMMUNICATION AND CULTURAL CONSTRAINS}

The responses from the selected stakeholders reveal that part of the challenges in sustaining the collaborative partnerships in this study concerns ambiguous communication and cultural issues among the stakeholders. Even though all orphanages signed a memorandum of understanding (MOU) to join the partnership, they claimed a lack of clear communication as a main challenge. Where there was no communication or follow up of the programmes, the orphanage administrators were most likely to make their own assumption. The challenge of communication was also voiced by the volunteers and the service organisation. Although the participants seemed to share similar cultural values, and the partnership practised flexible working, the findings reveal that there were some related cultural and structural constraints. In these terms, the service organisation, corporate, NGO, and volunteer participants discussed the difficulties of partners understanding different approaches, and the difficulties of volunteers adapting to cultural differences. The discussion on ambiguous communication and cultural constraints in a range of contexts comprise the challenge for all stakeholders, and the specific challenge between the service organisation and the Lions Club.

Table 1 provides the brief of the responses from the participants concerning the communication and cultural constraints among the stakeholders. While Table 2 presents the brief of responses from participants regarding the communication and cultural constraints between CyberCare and the Lions Club in particular.

Table 1. Communication and cultural constraints among the stakeholders

\begin{tabular}{|l|l|}
\hline Issues & Brief of the responses \\
\hline $\begin{array}{l}\text { Miscommunication with the } \\
\text { corporation }\end{array}$ & $\begin{array}{l}\text { Poor communication with the corporate partner led to a change } \\
\text { in agreement with the corporation. }\end{array}$ \\
\hline $\begin{array}{l}\text { Assumptions about discontinued } \\
\text { programmes }\end{array}$ & $\begin{array}{l}\text { Lack of communication, and follow-up programmes led the } \\
\text { orphanage administrators to assume that the programmes were } \\
\text { discontinued. }\end{array}$ \\
\hline $\begin{array}{l}\text { Imprecise collaborative } \\
\text { partnership's benefits }\end{array}$ & $\begin{array}{l}\text { Ineffective communication of the programme benefits to the } \\
\text { partners can lead them to become suspicious }\end{array}$ \\
\hline $\begin{array}{l}\text { Lack of direction in moving } \\
\text { forward }\end{array}$ & $\begin{array}{l}\text { Unsatisfactory communication from the service organisation } \\
\text { left partners without direction }\end{array}$ \\
\hline $\begin{array}{l}\text { Difficulties in adapting to cultural } \\
\text { and religious differences }\end{array}$ & $\begin{array}{l}\text { Cultural differences between volunteers and coaches made it } \\
\text { hard for volunteers to adapt the coaches' ideas. }\end{array}$ \\
\hline
\end{tabular}


Table 2. Communication and cultural constraints between CyberCare and the Lions Club

\begin{tabular}{|l|l|}
\hline Issues & Brief of the responses \\
\hline $\begin{array}{l}\text { Adhering to the protocols of } \\
\text { the Lions Club }\end{array}$ & $\begin{array}{l}\text { The impression is created that in order for club members to be } \\
\text { accepted and gain support from other club members, they had to } \\
\text { attend all the club meetings and functions where not all members were } \\
\text { in tune with the practice. }\end{array}$ \\
\hline $\begin{array}{l}\text { Different understandings of } \\
\text { sponsorship promotion }\end{array}$ & $\begin{array}{l}\text { CyberCare valued the right of those who provide financial support to } \\
\text { CyberCare to be promoted more but the Lions Club may see that they } \\
\text { should be given greater priority as a patron to the organisation. }\end{array}$ \\
\hline $\begin{array}{l}\text { Difficulties in } \\
\text { understanding different } \\
\text { organisational approaches }\end{array}$ & $\begin{array}{l}\text { The difficulties in understanding each other's ways of carrying out } \\
\text { programmes, due to different cultural approaches within the } \\
\text { organisations. }\end{array}$ \\
\hline $\begin{array}{l}\text { Disputes over shared } \\
\text { resources }\end{array}$ & $\begin{array}{l}\text { The disputes over the resources collected under the "Lions Club of } \\
\text { CyberCare } \\
\text { CyberCare decided to wise when } \\
\text { network }\end{array}$ \\
\hline
\end{tabular}

The issues dealing with communication and culture between stakeholders in this collaborative partnership setting showed that the stakeholders (especially from the group of orphanage administrators and volunteers) strongly valued continuing commitment in the programme, and constant and clear communication with the partners in sustaining collaborative partnership. However, these stakeholders only emphasised the need for constant communication with the service organisation, rather than with all of the stakeholders involved. This further explains the dyadic relationships that exist between the two stakeholders in this collaborative partnership. The challenge of communication and culture in specific to CyberCare and the Lions Club dealt more with organisational working cultures.

\section{THE NEED OF COMMUNICATION AND NURTURING TO SUSTAIN THE COLLABORATIVE PARTNERSHIP}

The lack of clarity and transparency in communication led to negative assumptions which may threaten relationships and implementation. For example, one of the orphanage administrators suspected that CyberCare had a hidden agenda to attract sponsors in asking for the participation of children from his orphanage. This was because CyberCare did not clearly explain to the administrator the details of the programme and the way the orphanage could benefit from participation.

The findings support previous studies that emphasise the importance of constant communication and nurturing in sustaining collaborative efforts [1-2], [14], [5, 13]. At first glance, it might seem that my study suggests that this collaborative partnership was lacking the aspects of nurturing and communication which are important to sustain the collaborative efforts and relationships. However, some of these conflicts are structural (such as the timescale of interns from university, and the anxieties of orphanage administrators about the internet's influence on children), in which case they are not easily resolved via communication.

Even in situations where collaboration is running well with a relative degree of trust, Vangen and Huxham [5] emphasise the need for continuous nurturing to sustain satisfactory levels of trust, and Wildavsky [8] suggests careful nurturing to renew partners' enthusiasm during the process. The lack of such constant communication and nurturing as revealed in this study has impacted the collaborative partnership's structure and implementation of its programmes. The most significant impact was seen in relationships 
with the orphanages as perceived by the orphanage administrators. Despite the agreement at the beginning of the partnership, due to the gap in communications some of the orphanage administrators were still uncertain of their partnership status: whether to consider their orphanages as partners or to regard CyberCare as a partner. On top of this, not all of them viewed the programmes as sustained. It is not just constant communication that is required to carry the collaborative partnership forward, but more than that, it is important for communication to be clear and transparent.

While the worldwide network of innovators of multi-stakeholder partnerships in the area of ICT for development, GKP [9] regarded implementation of a properly structured partnership agreement as able to ensure continuing communication and transparency, this thesis has argued that correct implementation based on initial agreement cannot resolve communication problems in all partnership settings. For example, in this study, there are a few cases of miscommunication and lack of transparency even after the partners have formally agreed on the related procedures and what they wanted to work on collaboratively. This shows that having a well-structured agreement is not the only factor ensuring on-going communication and transparency. In addition, some scholars [1] take the view that "communication among partners is based more on interdependent relationships than on contractual agreements" as presented in my study. This is due to the complexity in implementing collaboration, the voluntary participation, autonomous actors, and less visible traditional management systems like "hierarchy, standardisation, and routinisation"[1]. This may explain why some participants in my study expressed the need to have a more organised management structure in CyberCare.

Besides the issues mentioned, there were also some advantages to the styles of communication practised in this collaborative setting. This was portrayed in this study where some decisions to join or continue with the collaborative efforts made by individuals within the partnerships were because of the political or social links between them which McQuaid [15] refers as informal structure. It was the informal structure of the partnership [15] through the established informal relationship and communication which drove this collaborative partnership forward. This finding also supported Perrault et al [14] view that established informal relationships and communication can contribute to successful community collaboration. For example, the main representative of CyberCare (YW-SO) used to help the representative from the Lions Club (SL-NGO) with the Lions Club programmes before CyberCare was formed as a Lions Club. The relationship built through the programmes led YW-SO to approach SL-NGO, and SL-NGO to agree to collaborate. This partnership used both informal ways of communicating, like text messages, and more formal means such as meetings of the board members. Established informal relationships provided flexibility for CyberCare members to achieve collaborative decisions like discussing collaborative plans and programmes in a member's home or in a cafe while at the same time reaching professional/formal decisions. This informal structure did not just contribute to the smooth running of the decision-making process especially when the project was conceived, but also led the stakeholders to develop the formal structure with general agreement to set up and carry out the collaborative project.

The ability of this collaborative partnership to survive through transformation was consistent with the conclusions of Melaville and others' [16] research, namely that a longterm collaborative partnership was enabled by a series of interrelated activities designed to solve the shared problems and create a new system of services for children and families. This process prompted changes in the system including integrating and restructuring services [16]. This research supports the view that change within collaborative partnerships is a positive outcome rather than a threat. Through the collaborative programmes, in the long run, some of the close partners in this collaborative partnership were aiming to change 
society's acceptance of the child-centric programmes and perception of the community service work.

I would like to express my heartfelt gratitude to my principal supervisor, Dr Nicole Matthews for her continuous support throughout my enduring PhD journey.

\section{REFERENCES}

1. A. M. Thomson, J. L. Perry, Public Adm. Rev. (Special Issue), 20-32, (2006)

2. C. Huxham, S. Vangen, Collaborative Governance: a new era of public policy in Australia? 29-44, (2008)

3. D. J. Wood, B. Gray, J. App. Behave.Sci.,27(2), (1991)

4. Overseas Development Institute and Foundation for Development Cooperation, Multi-stakeholder partnerships: issue paper, (2003)

5. S. Vangen, C. Huxham, J. Appl. Behave. Sci., 39(1), (2003)

6. B. Gray, Collaborating: finding common ground for multiparty problems, (1989)

7. B. Gray, D. J. Wood, J. Appl. Behav. Sci., 27(1), (1991)

8. A. Wildavsky, $P S, \mathbf{1 9}(2),(1986)$

9. Overseas Development Institute and Foundation for Development Cooperation, Multi-stakeholder partnerships: issue paper, (2003)

10. C. Huxham, S. Vangen, Managing to collaborate : the theory and practice of collaborative advantage, (2005)

11. S. Vangen, C. Huxham, Network Theory in the Public Sector: Building New Theoretical Frameworks, (2014)

12. C. Huxham, Public Ma. Rev., 5 (3), (2003)

13. S. Prins, J. Appl. Behave. Sci., 46(3), (2010)

14. E. Perrault, R. McClelland, C. Austin, J. Sieppert, Administration in Social Work, 35(3), (2011)

15. R. W. McQuaid, Public private partnerships : theory and practice in international perspective, (2000)

16. A. I. Melaville, M. J. Blank, G. Asayesh, Together we can: a guide for crafting a profamily system of education and human services, (1996) 